\title{
Age-related differences in medial prefrontal activation in response to emotional images
}

\author{
Christina M. LeClerc and Elizabeth A. Kensinger \\ Boston College, Chestnut Hill, Massachusetts
}

\begin{abstract}
Research has suggested that aging results in a "positivity effect," with young adults dwelling on negative information, and older adults attending to positive information. In order to understand age-related changes in emotional processing underlying this effect, the present fMRI study compared neural activity in young and older adults as they viewed positive, negative, and neutral images. Results indicated a striking age-related reversal in the valence of information eliciting activity within the ventromedial prefrontal cortex (VMPFC). Negative in comparison with positive images activated the VMPFC more for young adults, whereas positive in comparison with negative images activated the VMPFC more for the older adults. The VMPFC is a region associated with the processing of emotional information, and more specifically, with emotion generation and emotion regulation. Therefore, the present results suggest that age-related changes in these processes implemented by the VMPFC contribute to older adults" "positivity effect."
\end{abstract}

Our world is filled with stimuli that evoke emotional responses: A smiling child may bring us pleasure, whereas the sight of a spider may elicit a negative emotion. Although there has been extensive discussion about how best to characterize emotional experiences (for reviews, see Barrett, 2006; Izard, 2007; Panksepp, 2007), many believe that affect can be divided into two dimensions: valence and arousal. Valence refers to whether an experience is positive or negative, and arousal captures whether an experience is exciting/agitating or soothing/subduing (Russell, 1980).

Previous research has revealed preferential processing for items that elicit arousal in our environment (i.e., stimuli that elicit physiological activation, goal-directed behavior, and subjective experience/feelings; e.g., Hansen \& Hansen, 1988; Pratto \& John, 1991). This preferential processing increases the likelihood that emotional elements in our environments are detected and attended, and these arousal-based influences appear to be relatively preserved with aging. For example, young and older adults are faster and more accurate at detecting emotional stimuli embedded in complex visual arrays than they are at detecting neutral stimuli (Leclerc \& Kensinger, 2008; Öhman, Flykt, \& Esteves, 2001), and there are no age differences in the detection benefit for arousing stimuli (Leclerc \& Kensinger, 2008). Both age groups also are more likely to remember arousing emotional information than they are to remember nonarousing information (Kensinger, 2008).

Although these arousal-based influences appear relatively preserved with aging, research over the last two decades has indicated that significant developmental changes occur in valence-based processing, and more specifically, in the prioritization and regulation of emotion (reviewed by Mather, 2006). In particular, socioemotional selectivity theory (Carstensen, 1993) suggests that a change in time perspective - time seeming limited - can result in emotional goals becoming increasingly important. Because older adults are, by virtue of age, closer to the end of life, this theory posits that they should be more focused on optimizing their emotional experience than are young adults, who tend to view their time as more expansive. As a result, advancing age should be associated with an increased focus on emotional goals and increased attention to the emotional content of information (Carstensen, Fung, \& Charles, 2003). Consistent with this proposal, older adults are more likely than young adults to choose activities that bring them emotional fulfillment, such as spending time with close friends or family (Fung, Carstensen, \& Lutz, 1999). They also are more likely than young adults to focus on the emotional meaning of information or on how an experience has made them feel (reviewed by Carstensen \& Mikels, 2005; Mather \& Carstensen, 2005).

Older adults may also adopt new cognitive strategies to allow them to maintain positive affect in the face of negative age-related change (i.e., limited time remaining, physical and cognitive decline). One such strategy is older adults' tendency to spend proportionately more time processing positive emotional material and less time processing negative emotional material than young adults do (Mather \& Carstensen, 2005). Previous research has indicated agerelated differences in terms of valenced-based processing, in that older adults look at positive images longer than younger adults do (Isaacowitz, Wadlinger, Goren, \& Wilson, 2006), and they recall proportionally more positive information, and proportionally less negative information, than young adults do (Charles, Mather, \& Carstensen, 2003; Kennedy, Mather, \& Carstensen, 2004). This enhanced focusing on 
the positive has been referred to as an age-related "positivity effect" (Carstensen \& Mikels, 2005).

Although there is extensive behavioral evidence that older adults process emotional information differently than younger adults do, the neural changes that underlie these behavioral effects have not been established. Structural studies have not shed light on this issue because the regions implicated in emotional processing (e.g., the ventromedial prefrontal cortex $[\mathrm{PFC}]$ and the amygdala) are among those that undergo relatively modest structural changes with aging. For example, West $(1996,2000)$ suggested that the $\mathrm{PFC}$ is a heterogeneous region in terms of cognitive and behavioral influences, with the ventral and dorsal regions exhibiting different rates of structural and functional agerelated decline. Although both dorsolateral and ventromedial PFC regions undergo some age-related declines, the dorsal and lateral regions have been found to be affected by the normal aging process earlier and at a more rapid pace of decline than other PFC regions (Daigneault \& Braun, 1993; Mittenberg, Seidenburg, O’Leary, \& DiGiulio, 1989; Moscovitch \& Winocur, 1995; Parkin, 1997; Raz, 1996; Shimamura, 1994; West, 1996). By contrast, the structural decline in ventromedial PFC regions appears to be less extensive (Hedden \& Gabrieli, 2004; Mather, 2003). Similarly, the amygdala appears to be a region that is relatively structurally preserved with aging; although it does undergo some structural decline, its rates of decline tend to be less than those of many other regions (Daigneault \& Braun, 1993; Mittenberg et al., 1989; Moscovitch \& Winocur, 1995; Parkin, 1997; Raz, 1996; Shimamura, 1994; West, 1996).

These findings suggest that in order to understand the age-related changes in emotional processing, it is necessary to examine the function of emotion processing regions, and not just their structure, across the adult life span. Although past research has begun to establish the neural mechanisms supporting emotional processing in younger adults, little is known about the neural processing of emotional information in older adults or about the neural changes that may mediate older adults' changes in emotion processing, including their "positivity effect." Some studies have suggested that aging may affect amygdala function, with older adults showing decreased amygdala activation in comparison with young adults, particularly to negative facial expressions (e.g., Gunning-Dixon et al., 2003; Iidaka et al., 2002). However, a neuroimaging study examining age-related differences in amygdala activation to colored photographs revealed that older adults showed greater amygdala engagement for positive pictures than for negative ones, whereas this was not the case for younger adults (Mather et al., 2004). Thus, aging may not result in an overall decline in the functioning of the amygdala (see also Wright, Wedig, Williams, Rauch, \& Albert, 2006), but instead may result in a shift in the type of emotional stimuli to which the amygdala is most responsive. Aside from the amygdala, regions within the PFC are those that have most commonly been found to show age-related changes during emotion processing (e.g., Gunning-Dixon et al., 2003; Gutchess, Kensinger, \& Schacter, 2007; Samanez-Larkin et al., 2007; Tessitore et al., 2005; Williams et al., 2006).
The PFC has been found to downregulate amygdala activity in both young (e.g., Ochsner, Bunge, Gross, \& Gabrieli, 2002) and older (e.g., Urry et al., 2006) adults, and so these age-related changes in PFC recruitment have sometimes been taken as evidence for an age-related shift from relatively automatic to more controlled emotion processing (e.g., Williams et al., 2006). However, the directionality of these PFC changes is not clear. Some studies have revealed overrecruitment of PFC processes in older adults during the processing of negative affect (e.g., Gunning-Dixon et al., 2003; Tessitore et al., 2005; Williams et al., 2006), whereas other studies have found that older adults underrecruit the PFC during the processing of negative information (e.g., Gutchess et al., 2007; Samanez-Larkin et al., 2007). Because few studies have compared young and older adults' processing of positive and negative information equated on arousal (most have compared fearful with happy facial expressions, where happy expressions are likely to be lower in arousal), a likely contributor to these contradictory findings is the confluence of arousal-based and valence-based processes.

The goal of the present fMRI study was to investigate the underlying neural networks associated with the processing of emotional information in younger and older adults. We were particularly interested in examining the degree to which aging affected the PFC regions that respond in an arousal-based fashion (i.e., those that respond to positive and negative arousing items) versus those that respond in a valence-based fashion (e.g., more to negative than to positive items, or vice versa). To address these issues, participants viewed positive, negative, and neutral images and were asked to make a nonaffective, simple judgment about each image.

We hypothesized that aging might not modulate activity within the regions that mediate arousal-based influences in emotion processing, given the extensive evidence suggesting that aging may relatively preserve the effect of arousal on attention and memory (reviewed by Mather, 2006). On the basis of prior research, we hypothesized that the dorsomedial PFC would be a key region that would relate to arousal in young adults (see Dolcos, LaBar, \& Cabeza, 2004; Kensinger \& Schacter, 2006) and also in older adults. By contrast, we hypothesized that aging would be likely to alter the neural activity that corresponded with valencebased processing, consistent with behavioral evidence that older adults show a "positivity bias" (reviewed by Mather $\&$ Carstensen, 2005). We believed that age-related changes might be particularly prominent within the ventromedial PFC, a region previously implicated in valence-based processing (e.g., Anderson et al., 2003; Small et al., 2003) and in emotion regulation processes (reviewed by Davidson, 2002; Quirk \& Beer, 2006). Our rationale was that previous behavioral research has consistently observed age-related functional changes in emotion regulation abilities (Gross et al., 1997; Lawton, Kelban, Rajagopal, \& Dean, 1992) and in tasks associated with more controlled emotional processing (reviewed by Kensinger \& Leclerc, in press; Mather, 2006). We therefore reasoned that age-related changes might be particularly pronounced within the PFC regions that implement such processes. 


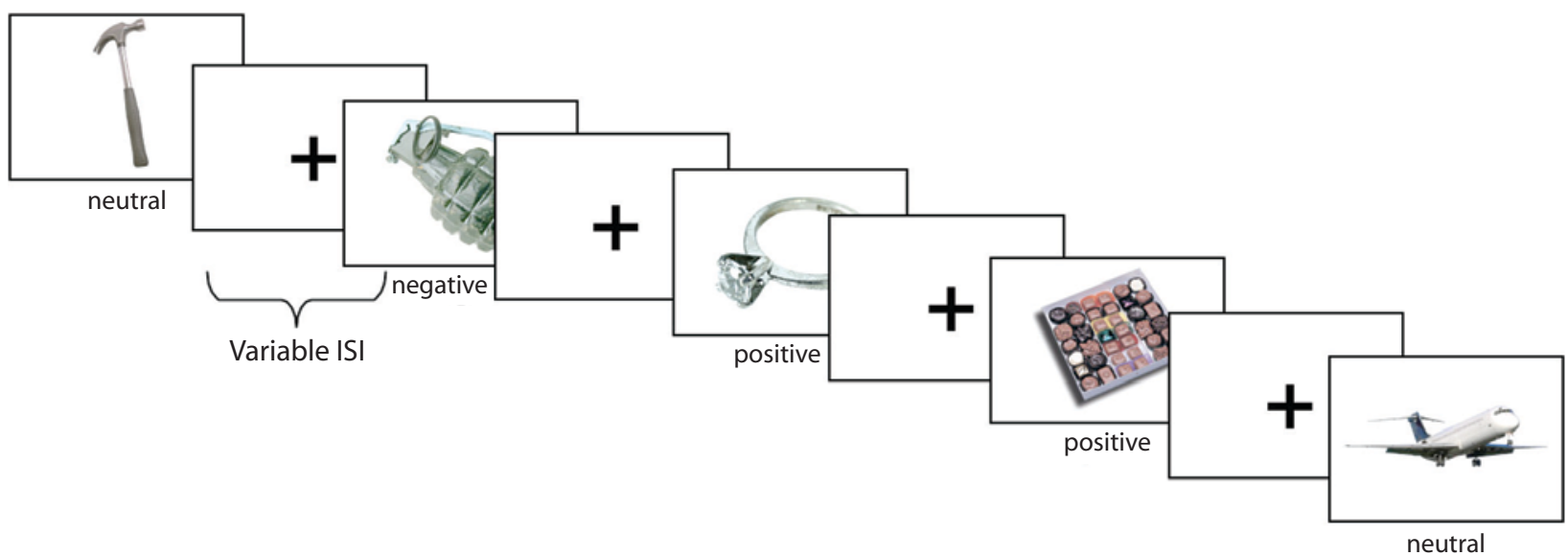

Figure 1. Task design. Participants viewed images that had been rated as positive and arousing (e.g., a diamond ring), negative and arousing (e.g., a grenade), or neutral (e.g., an airplane). Participants indicated, via a buttonpress, whether each item would fit inside of a file cabinet drawer.

\section{METHOD}

\section{Participants}

The participants were 17 younger adults ( 12 women) between the ages of 19 and 31 years and 20 older adults (13 women) between the ages of 61 and 80 years. All were right-handed native English speakers with no history of psychiatric or neurological disorders. No participant was taking any medication that would affect the central nervous system, and no participant was depressed. Informed consent was obtained from all the participants in a manner approved by the Boston College and Massachusetts General Hospital institutional review boards. Participants were compensated $\$ 75$ for their participation.

\section{Materials}

Stimulus images used in the present article were selected from a larger set of colored images previously rated by a separate group of 24 young and 24 older adults on valence and arousal dimensions, using 9-point Likert-type scales $(1=$ negative valence or low arousal and $9=$ positive valence or high arousal). In addition, these images were also normed for complexity, colors present, and size. No systematic differences existed across the different emotional categories. Stimuli from each emotion category also were selected from the same number of semantic categories. Images used in the present study represented single objects (i.e., an ice cream sundae depicted on a white background) in contrast to complex scenes (see Figure 1). One third of the images selected were negative and high arousal (valence ratings less than 3.5, arousal ratings higher than 5), one third were positive and high arousal (valence higher than 5.5, arousal higher than 5), and one third were neutral (valence ratings between 3 and 6, arousal less than 5). The positive and negative images did not differ from one another in arousal nor in absolute valence $(p>.15)$. Positive and negative images were selected to be significantly more arousimng than neutral images $(p<$ $.001)$. Images were selected so that the valence and arousal ratings for each group of images (e.g., for positive images) did not differ for the young and older adults (all $p \mathrm{~s}>.15$; see Table 1 ).

Participants in the present study also rated these stimuli for valence and arousal after the completion of the experimental task. Their stimulus classifications generally corresponded with those obtained from using the ratings from this separate group of participants. In the rare instances ( $<2 \%$ of all items) when participant ratings did not match with the previously assigned ratings, participant ratings were used to classify the images as positive, negative, or neutral.

\section{Procedure}

While in the fMRI scanner, participants were presented with 324 (108 positive, 108 negative, 108 neutral) nameable, colored images. These images were presented across three lists, each containing 36 exemplars from each valence category. Each trial began with a white fixation cross presented on a black screen for $1,000 \mathrm{msec}$; the image was then presented, and it remained on the screen for 1,000 msec. After each image was presented, an intertrial fixation cross was presented for a variable duration, ranging between 5 and $13 \mathrm{sec}$, to provide jitter (Dale, 1999). The order of items was pseudorandomized for each participant, so that no more than four items of a particular valence were presented sequentially. Participants were instructed to make a keypress for each trial, as quickly as possible, to indicate whether the object depicted in each image, in the real world, would fit inside of a file cabinet drawer. Although the image was presented on the screen for only $1,000 \mathrm{msec}$, and participants were asked to make their response as quickly as possible, they were informed that their buttonpress would still be recorded if it was made after the image had been removed from the screen (i.e., during the jittered intertrial fixation period). This task was chosen because prior research has demonstrated that age-related changes in emotional processing are most apparent when tasks do not require participants to directly evaluate the emotional nature of the stimuli (discussed by Mather, 2006). Indeed, the encoding manipula-

Iable 1

Valence and Arousal Ratings for the Stimuli Used in the Present Study

\begin{tabular}{|c|c|c|c|c|c|c|c|c|c|c|c|c|}
\hline \multirow[b]{3}{*}{ Group Ratings } & \multicolumn{6}{|c|}{ Valence } & \multicolumn{6}{|c|}{ Arousal } \\
\hline & \multicolumn{2}{|c|}{ Positive } & \multicolumn{2}{|c|}{ Negative } & \multicolumn{2}{|c|}{ Neutral } & \multicolumn{2}{|c|}{ Positive } & \multicolumn{2}{|c|}{ Negative } & \multicolumn{2}{|c|}{ Neutral } \\
\hline & $M$ & $S E$ & $M$ & $S E$ & $M$ & $S E$ & $M$ & $S E$ & $M$ & $S E$ & $M$ & $S E$ \\
\hline Young adults & 7.02 & 0.23 & 2.44 & 0.26 & 5.15 & 0.17 & 6.61 & 0.28 & 6.89 & 0.21 & 3.99 & 0.19 \\
\hline Older adults & 7.13 & 0.31 & 2.27 & 0.35 & 5.53 & 0.31 & 6.32 & 0.31 & 6.44 & 0.35 & 3.89 & 0.24 \\
\hline
\end{tabular}

Note-Valence and arousal were rated on 9-point scales (high values indicating positive valence and high arousal, respectively). 
tion used here has been shown to lead to a robust positivity shift in memory, with young adults showing a memory benefit only for negative stimuli but older adults showing a robust memory benefit for positive stimuli (Kensinger, Garoff-Eaton, \& Schacter, 2007).

\section{Image Acquisition and Data Analysis}

Images were acquired on a 3.0 Tesla Siemens Allegra MRI scanner. Stimuli were back-projected onto a screen in the scanner bore, and the participants viewed the images through an angled mirror attached to the head coil. Detailed anatomic images were acquired using a multiplanar rapidly acquired gradient echo sequence. Functional images were acquired using a $\mathrm{T} 2 *$-weighted echo planar imaging sequence $(\mathrm{TR}=3,000 \mathrm{msec}, \mathrm{TE}=30 \mathrm{msec}, \mathrm{FOV}=200 \mathrm{~mm}$; flip angle $=90^{\circ}$ ). Twenty-eight axial-oblique slices (3.2-mm thickness, 0.6-mm skip between slices), aligned in a plane along the axis connecting the anterior commissure and the posterior commissure, were acquired in an interleaved fashion.

All preprocessing and data analysis were conducted within SPM2 (Wellcome Department of Cognitive Neurology). Standard preprocessing was performed on the functional data, including slicetiming correction, rigid body motion correction, normalization to the Montreal Neurological Institute template (resampling at 3-mm cubic voxels), and spatial smoothing (using 7.6-mm full-width halfmaximum isotropic Gaussian kernel).

An event-related analysis was conducted for each participant; on a voxel-by-voxel basis, all instances of a particular event type were modeled through convolution with a canonical hemodynamic response function. Effects for each event type (positive image, negative image, neutral image) were estimated using a subject-specific, fixed effects model. These data were then entered into a secondorder, random effects analysis.

We primarily were interested in identifying two types of regions: those that responded to all high-arousal stimuli regardless of valence, and those that responded in a valence-based fashion. To find regions that responded in an arousal-based fashion, we first conducted a random effects contrast analysis, using the one-sample $t$ test function with SPM (with between-participants variability to estimate variance) to examine the voxels in which activity was consistently greater for negative than for neutral stimuli or for positive than for neutral stimuli. We then performed a conjunction analysis, using the masking function in SPM, to test for the regions in which activity was enhanced for positive in comparison with neutral stimuli and also for negative in comparison with neutral stimuli (i.e., positive $>$ neutral AND negative $>$ neutral). We performed these conjunction analyses separately in each age group, with the individual contrasts included in the contrast analysis analyzed at a threshold of $p<.01$ (such that the conjoint probability of the conjunction analysis, using Fisher's estimate [Fisher, 1950; Lazar, Luna, Sweeney, \& Eddy, $2002]$, was $p<.001$ ). Only regions consisting of at least a 5-voxel extent were considered reliable. We then looked for regions showing a similar arousal-based response in each age group by performing a four-way conjunction (i.e., negative $>$ neutral for young adults AND positive $>$ neutral for young adults AND negative $>$ neutral for older adults AND positive $>$ neutral for older adults). We also used the inverse masking function within SPM to look for regions that appeared in one age group's conjunction analysis map but not in the other group's map (e.g., regions that responded for negative $>$ neutral and positive $>$ neutral for young adults but not for both negative $>$ neutral and positive $>$ neutral older adults).

To examine the regions that responded in a valence-based fashion, we performed contrast analyses separately for each age group in order to reveal the regions that were more responsive to positive than to negative items, or vice versa. To examine the regions that responded in a valence-based fashion for the young and older adults, we performed conjunction analyses, using the masking function in SPM, to identify the regions that showed the same pattern of response (e.g., greater activity for positive than for negative items) for both age groups. Each contrast entered into the conjunction analysis was analyzed at a threshold of $p<.01$ and with a 5-voxel extent. To ex- amine the regions that responded in a different fashion for the young and older adults, we performed group comparison analyses using the two-sample $t$ test function within SPM. Note that these group analyses reveal a number of potential patterns: a stronger, valence-based response in one group than the other, but with both groups showing the same direction of response (e.g., negative $>$ positive for young adults, negative $>$ positive for older adults), a strong response in one group and a null effect in the other (e.g., negative $>$ positive for young adults, negative $=$ positive for older adults), or a reversal in the directionality of the response (e.g., negative $>$ positive for young adults, positive $>$ negative for older adults). To characterize the pattern of activity, we created regions of interest (ROIs) that included all significant voxels within a 5-mm radius of each maximum voxel revealed by the group comparison analyses (using the ROI toolbox implemented in MarsBar; Brett, Anton, Valabregue, \& Poline, 2002). We then extracted the hemodynamic time course for each individual participant and for each condition type (relative to fixation baseline) as a function of peristimulus time $(0-21 \mathrm{sec})$. Statistics were performed on the sum of the signal change occurring between $3 \mathrm{sec}$ and $12 \mathrm{sec}$ poststimulus onset. These sum of signal change values are displayed in the figures. ANOVAs were performed on these extracted signal change values to examine whether the ROIs showed a main effect of emotion type (i.e., activity greater for one valence than another) or an interaction between age and emotion type.

All activations are presented in neurological coordinates (i.e., activity on the right hemisphere is presented on the right side of the brain images). Voxel coordinates are reported in Talairach coordinates (Talairach \& Tournoux, 1988) and in Montreal Neurological Institute (MNI) coordinates (Collins et al., 1998) and reflect the most significant voxel within the cluster of activation.

\section{RESULTS}

\section{Behavioral Responses}

Analyses revealed that the emotional nature of the item (positive, negative, or neutral) did not affect young or older adults' reaction times to make the decisions about the images $(F<1)$. There was, however, a main effect of age on reaction time $[F(1,35)=32.49, p<.001]$. As expected, older adults were significantly slower to make the decisions (mean RT for positive images $=2,003 \mathrm{msec}$, for negative images $=2,032 \mathrm{msec}$, for neutral images $=$ $2,003 \mathrm{msec}$ ) than were young adults (mean RT for positive images $=1,391 \mathrm{msec}$, for negative images $=1,304 \mathrm{msec}$, for neutral images $=1,345 \mathrm{msec}$ ). Participants performed the task accurately; fewer than $2 \%$ of all responses were inaccurate (mean accuracy for young adults $=99.4 \%$ for positive images, $99.2 \%$ for negative images, $99.1 \%$ for neutral images; mean accuracy for older adults $=98.5 \%$ for positive images, $98.7 \%$ for negative images, $98.9 \%$ for neutral images) and neither emotion nor age had an effect on response accuracy $(F<1)$.

\section{Arousal-Based Responses}

As outlined in the methods, we performed a four-way conjunction analysis to examine the regions that responded to all high-arousal stimuli for both young and older adults (i.e., negative $>$ neutral for young adults AND positive $>$ neutral for young adults AND negative $>$ neutral for older adults AND positive $>$ neutral for older adults; see Table A1 in the Appendix for the regions that were revealed in each of these four individual contrasts). Two regions showed this arousal-based response for both age groups (see Table A2), including the dorsomedial 
PFC (DMPFC; Figure 2, region outlined in blue; Talairach coordinates $8,61,15$ for positive $>$ neutral AND negative $>$ neutral; BA 10). A 2 (age) $\times 3$ (item type) repeated measures ANOVA conducted on the sum of the signal change in this region of the DMPFC confirmed that there was a main effect of age [greater deactivation across all three valence categories for the older adults in comparison with the younger adults; $F(1,35)=4.43, p<$ $\left..04 ; \eta_{\mathrm{p}}^{2}=.11\right]$. There was also a significant main effect of item type [similarly high activation to positive and negative stimuli, and significantly lower activation to neutral stimuli; $F(2,70)=4.00, p<.03 ; \eta_{\mathrm{p}}^{2}=.10$ ], but a nonsignificant interaction between item type and age group $\left[F(2,70)=0.03, p>.96 ; \eta_{\mathrm{p}}^{2}=.001\right]$. Critically, inverse masking revealed no regions that appeared in the young adults' conjunction analysis and not in the older adults' conjunction analysis. There was one region of the insula (Talairach coordinates: $32,22,17$ ) that was revealed in the older adults' conjunction analysis at the standard threshold but only in the young adults' conjunction analysis at a lower threshold $(p<.05$ for each contrast within the conjunction). Although this region showed a numerically stronger relation to arousal in older adults than in young adults, the interaction between age and arousal response did not reach significance $(F<1)$ and the region showed a relation to arousal in both age groups.

\section{Valence-Based Responses}

To examine regions that showed a differential response based on valence, we contrasted activity for high-arousal positive images with activity for high-arousal negative items (and vice versa) for both age groups. Because positive and negative images were statistically matched in arousal across both age groups, activation differences between the positive and negative images should be related to differences in valence. Conjunction analyses revealed that there were some commonalities in young and older adults' valencebased responses (see Table A3 for regions activated similarly for younger and older for positive $>$ negative, as well as regions activated similarly across both age groups for

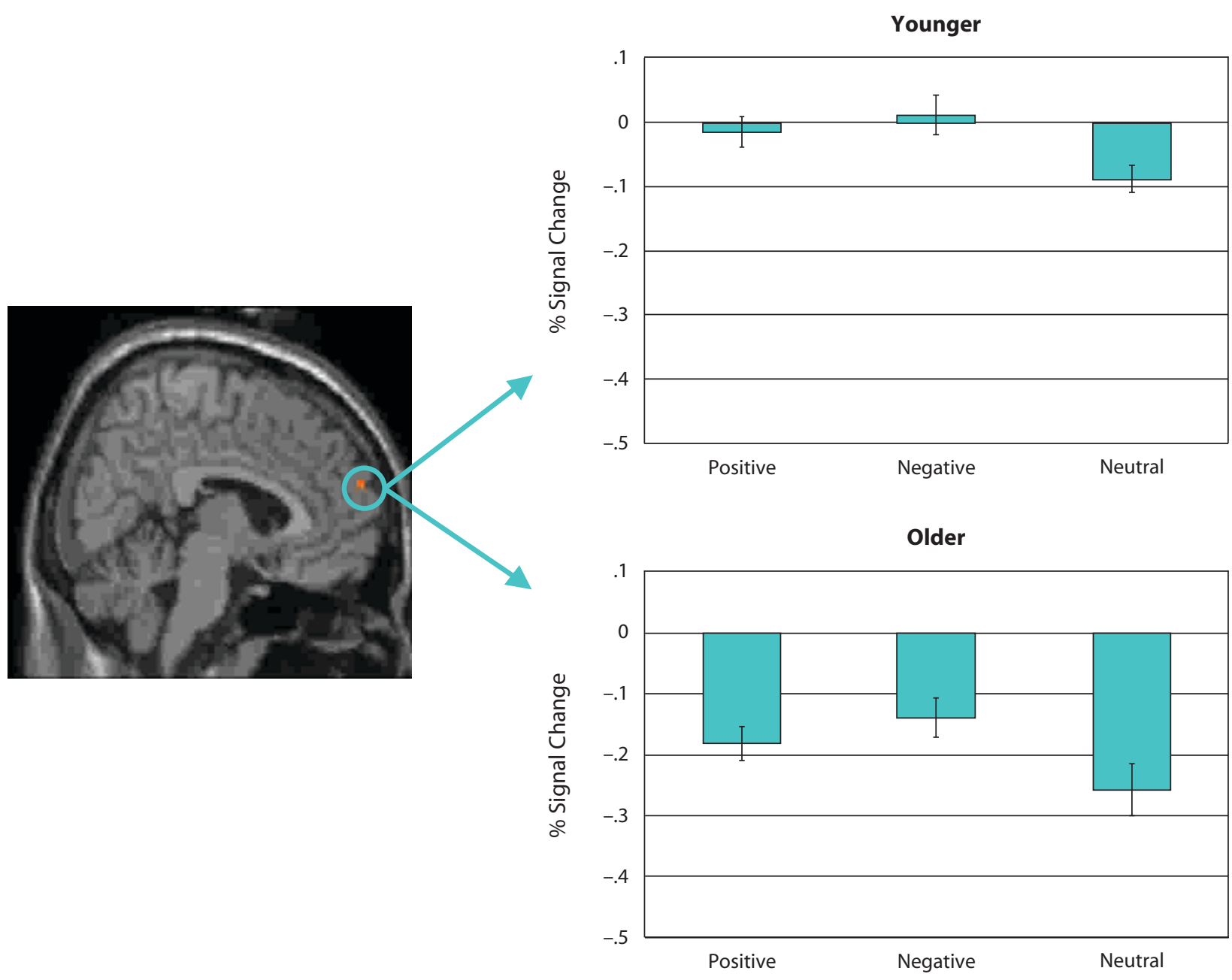

Figure 2. A DMPFC region (Talairach coordinates $8,61,15$; BA 10) showed similar patterns of arousal-based (i.e., valenceindependent) activation for both younger and older adults. Graphs indicate greater (i.e., less negative) activation for positive and negative images than for neutral across both younger and older adults (i.e., positive $>$ neutral AND negative $>$ neutral as confirmed by post hoc $t$ tests; both $p s<.001$ ). (Both positive and negative stimuli were rated highly arousing, whereas neutral stimuli were rated low in arousal; error bars represent standard error values.) 
negative $>$ positive). However, group comparison analyses also indicated that there were important group differences in the valence-based responses. Consistent with our hypothesis that age-related changes in emotion processing would arise within the prefrontal cortex, a ventral region of the medial prefrontal cortex (MPFC) - extending into the ventral anterior cingulate gyrus - activated significantly, as did a few other regions ${ }^{1}$ (see Table A4). Interestingly, when we extracted hemodynamic time courses from these regions, those time courses revealed that each of these regions displayed a valence reversal (i.e., negative $>$ positive in younger adults and positive $>$ negative in older adults; see Table A3). For example, the ventral MPFC activated more strongly in younger adults for negative than for positive images (Figure 3; region outlined in purple, Talairach coordinates $0,39,-5$; BA 32), whereas the same region responded more strongly in older adults for positive than for negative images. This age-related reversal in valence-based responding was confirmed by a 2 (age) $\times 2$ (valence) repeated measures ANOVA, which revealed a significant age $\times$ valence interaction [negative $>$ positive in younger and positive $>$ negative in older; $\left.F(1,35)=5.87, p<.02 ; \eta_{\mathrm{p}}^{2}=.14\right]$.

\section{DISCUSSION}

Results of the present study revealed two separate patterns of neural activation within the prefrontal cortex: A dorsomedial prefrontal region was modulated by stimulus arousal, whereas a ventromedial region responded based on stimulus valence. In general, the brain regions modulated by the stimulus arousal dimension displayed similar patterns of response in both younger and older adults. By contrast, regions activated more by the stimulus valence dimension showed an age-related valence-based reversal in patterns of activation. These results are consistent with mounting evidence that arousal-based processing may be relatively preserved with aging, whereas valence-based processing may undergo significant age-related change.

The arousal-dependent (and valence-independent) response of the DMPFC region is consistent with the findings of Kensinger and Schacter (2006) and Dolcos et al. (2004), who presented participants with positive, negative, and neutral photographs from the IAPS set (Lang, Bradley, \& Cuthbert, 2005). Despite the fact that these prior studies used a separate paradigm and set of stimulus images, these
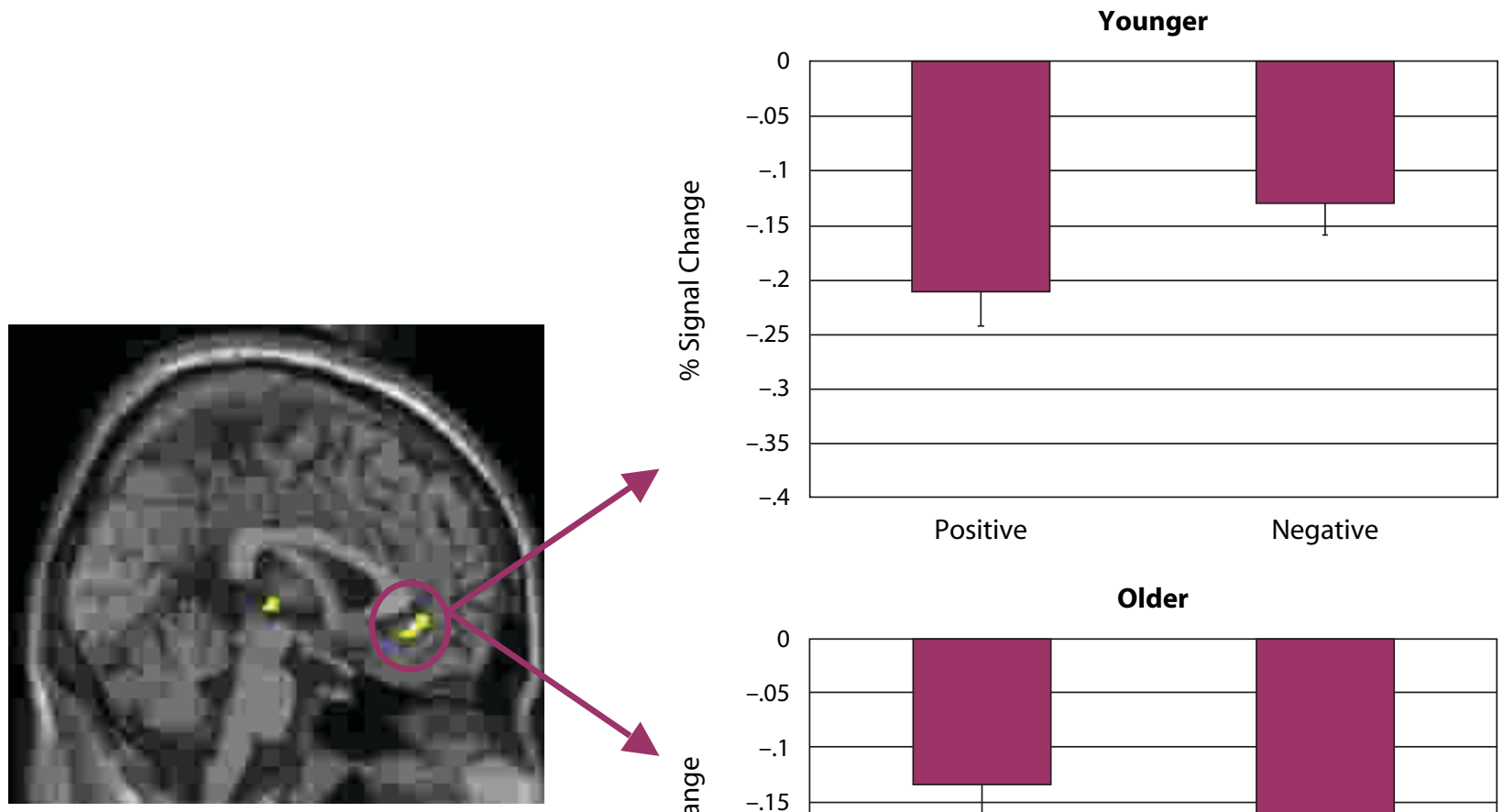

Older

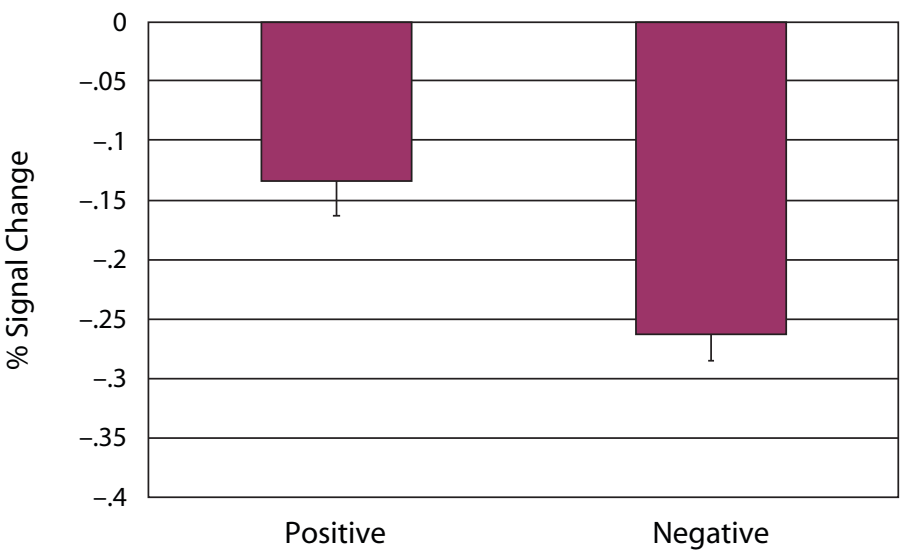

Figure 3. A VMPFC/anterior cingulate region (Talairach coordinates $0,39,-5 ; \mathrm{BA} \mathrm{32}$ ) activated more strongly in younger adults for negative than for positive images (top panel) and activated more strongly in older adults for positive than for negative images (bottom panel). The graphs highlight this valence reversal with greater (i.e., less negative) activation for the negative images in young adults (top) and for the positive images in older adults (bottom). Error bars represent standard error values. 
researchers also reported greater activity in the DMPFC (Talairach coordinates 3, 54, 28; BA 9/10) for high-arousal versus low-arousal image stimuli. Thus, the DMPFC appears to show consistent, arousal-based processing (see also Anders, Lotze, Erb, Grodd, \& Birbaumer, 2004; Grimm et al., 2006). The fact that the pattern of DMPFC response in the present work was comparable in the two age groups suggests agerelated preservation of the mechanisms supporting arousalbased processing. This finding is generally consistent with behavioral evidence suggesting that older adults, like young adults, rapidly detect arousing information (Hahn, Carlson, Singer, \& Gronlund, 2006; Leclerc \& Kensinger, 2008; Mather \& Knight, 2006) and show robust mnemonic benefits for arousing information (Kensinger, 2008).

In contrast to the pattern of response in the DMPFC, the VMPFC/anterior cingulate displayed valence-based patterns of activation that were age-dependent. Activity in this region was greater in young adults for negative versus positive emotional images, whereas in older adults, activity was greater for positive versus negative images. The VMPFC/ anterior cingulate is a region that has previously been implicated in the processing of emotional valence (see, e.g., Anderson et al., 2003; Dolcos et al., 2004; Grimm et al., 2006; Small et al., 2003). The present results suggest that this region continues to play a role in valence-based processing across the adult life span. However, although its activity is valence based for both young and older adults, the nature of that valence-based response appears to change across the life span. This valence reversal within the VMPFC/anterior cingulate parallels behavioral age-related reversals in the types of information that are most likely to sustain attention and be remembered. Across a range of tasks, particularly those that involve social-information processing, young adults tend to show a "negativity bias," sustaining attention on negative rather than positive stimuli, and remembering negative items more often (Pratto \& John, 1991). By contrast, older adults often show a "positivity effect" (Carstensen \& Mikels, 2005).

Prior studies have revealed that the VMPFC plays a critical role in emotion processing. According to extensive meta-analytic reviews, the VMPFC/anterior cingulate is activated in response to a range of emotions (Phan, Wager, Taylor, \& Liberzon, 2002) and may play a role in a wide range of behavioral outputs including appraisal, evaluation, as well as emotional experience and expression (e.g., Lane, Reiman, Ahern, Schwartz, \& Davidson, 1997; Lane, Reiman, Bradley, et al., 1997). The VMPFC/anterior cingulate may be particularly important for the cognitive aspects associated with emotional processing, such as attention toward and identification of emotional feelings (Drevets \& Raichle, 1998). Consistent with these suggestions, individual differences in the resting state activity within the VMPFC predict the extent to which negative affect is experienced (Zald, Mattson, \& Pardo, 2002), and activation within the VMPFC can correspond with ratings of stimulus valence (e.g., Anderson et al., 2003; Small et al., 2003). Given this prior evidence, it makes good sense that a reversal in the valence-based responding of the VMPFC could lead to changes in the allocation of attention to emotional stimuli, or in the elaborative processing of emotional stim- uli, which could lead, in turn, to young adults' "negativity bias" and to older adults' "positivity effect."

Although the present study cannot directly elucidate the mechanism through which the reversal in the valencebased responding occurs, we believe that the fact that such age-related reversals occurred within the VMPFC (and not within other regions of the limbic system) is consistent with the suggestion that older adults" "positivity effect" may arise from changes in controlled emotional processing or in emotion regulation. The hypothesized link between controlled emotion processing and older adults' "positivity effect" has been proposed based on behavioral evidence. In particular, Mather and Knight (2005) found that, when asked to process emotional images while performing an effortful divided attention task, older adults' "positivity effect" was eliminated. Older adults, just like young adults, remembered more negative than positive images. Thus, when older adults' cognitive control resources were limited, reducing their ability to regulate their responses to emotional information, they showed no "positivity effect." This link between cognitive control processes and the "positivity effect" was further substantiated by the finding that older adults with good cognitive control showed a larger "positivity effect" than those with poorer cognitive control (Mather \& Knight, 2005). Because regions such as the VMPFC and anterior cingulate have been previously implicated in more controlled stages of emotional processing (Drevets \& Raichle, 1998; Lane, Reiman, Ahern, et al., 1997; Lane, Reiman, Bradley, et al., 1997), the present results dovetail nicely with those previous behavioral findings.

An intriguing possibility raised by the present study is that age-related changes in the processing of positive information may be connected to self-referential processing. The VMPFC has been connected to self-referential processing and to representations of stable knowledge regarding the self (e.g., stable personality traits and dispositions in contrast to transient states; D'Argembeau et al., 2005). Thus, when people are asked to process information in a self-relevant manner (e.g., deciding whether adjectives describe them), activity in the VMPFC is greater than in conditions in which people process information in reference to others (e.g., deciding whether adjectives describe President Bush; Johnson et al., 2002; Schmitz, Kawahara-Baccus, \& Johnson, 2004). This tie between VMPFC activity and self-referential processing occurs for older adults as well as for young adults (Gutchess et al., 2007). In fact, this tie between MPFC activity and self-referential processing may explain the belowbaseline response shown in this task, as in most prior studies examining MPFC response (e.g., D'Argembeau et al., 2005; Johnson et al., 2005; Kensinger \& Schacter, 2006). The fact that these regions tend to show the highest activity levels during baseline has been proposed to reflect the fact that self-referential processing is likely to be a "default mode" of processing, carried out during the baseline periods (Gusnard \& Raichle, 2001): When participants are not given a task to perform, they are likely to think about themselves things they need to do, things that have happened to them, and so on. Thus, when task-related trials occur, participants actually disengage these self-referential processes and shift toward other processes that allow them to perform the ex- 
perimental task. This shifting away from self-referential processing results in a below-baseline response during the experimental trials. Based on this idea of a default mode of activity, the present results may suggest that older adults disengage self-referential processes far less for positive items than for negative items. One possible explanation of this effect is that older adults might be more likely to process positive, rather than negative, information in reference to themselves. For example, when older adults see a diamond ring, perhaps they think of their own engagement ring or their own wedding day, whereas they may be less likely to engage in such self-referential processing of negative information. By contrast, the opposite might be true for young adults (and see Baumeister, Bratslavsky, Finkenauer, \& Vohs, 2001, for evidence that young adults process negative information in a self-relevant fashion). Although the present study cannot make a direct link between self-referential processing and older adults" "positivity effect," we believe that investigating the validity of such a connection will be a worthwhile pursuit for future research.

Although the present results are consistent with the suggestion that age-related changes arise at more controlled stages of emotion processing (as discussed by Mather, 2006), it is important to note that the present results also could be accounted for by age-related changes in more automatic aspects of emotion generation or emotion experience. As noted above, the VMPFC has been implicated in nearly all aspects of emotional experience, expression, recognition, and regulation (e.g., Cooney, Joormann, Atlas, Eugene, \& Gotlib, 2007; Drevets \& Raichle, 1998; Heberlein, Padon, Gillihan, Farah, \& Fellows, 2008; Lane, Reiman, Ahern, et al., 1997; Lane, Reiman, Bradley, et al., 1997). Age-related changes in any of these aspects could contribute to the valence reversal within this region.

In conclusion, although further work is required to more completely understand the regions of the brain associated with emotional processing across the life span, the present article provides evidence of both functional differences and similarities throughout aging. In particular, although prior studies had revealed structural preservation of the MPFC with aging, the present study reveals a ventral region of the MPFC that is quite distinct functionally in older adults, and a DMPFC region whose function is age invariant. Greater activation was observed in the DMPFC for younger and older adults when processing high-arousal versus lowarousal images, whereas activity in the VMPFC/anterior cingulate was greater in young adults for negative versus positive emotional images and greater in older adults for positive versus negative images. Based on these findings, we suggest that regions of the prefrontal cortex may not only be differentially affected by age-related decline, but also may process different aspects of emotional stimuli. Ventral regions of the PFC may activate differentially based on valence and age, whereas more dorsal regions may activate consistently across age groups, regardless of stimulus valence. Age-related preservation of DMPFC arousal-based processing, and age-related changes in $\mathrm{VMPFC} /$ anterior cingulate valence-based processing, align well with behavioral evidence suggesting that older adults retain normal arousal-based influences on attention and memory (Hahn et al., 2006; Kensinger, 2008; Mather \& Knight, 2006) but show changes in valence-based influences (Carstensen \& Mikels, 2005; Charles et al., 2003; Isaacowitz et al., 2006; Kennedy et al., 2004; Kensinger, 2008; Mather \& Carstensen, 2005). Taken together, these findings suggest that at least some of the age-related changes in emotion processing arise due to the patterns of age-related preservation versus alteration of function with regions of the MPFC.

\section{AUTHOR NOTE}

This research was supported by Grant BCS 0542694 from the National Science Foundation (E.A.K.) and by the Dana Foundation. E.A.K. was partially funded as a fellow of the American Federation for Aging Research. Correspondence concerning this article should be addressed to C. M. Leclerc, Department of Psychology, Boston College, McGuinn Hall, Room 512, 140 Commonwealth Ave., Chestnut Hill, MA 02467 (e-mail: christina.leclerc.1@bc.edu).

\section{REFERENCES}

Anders, S., Lotze, M., Erb, M., Grodd, W., \& Birbaumer, N. (2004). Brain activity underlying emotional valence and arousal: A responserelated fMRI study. Human Brain Mapping, 23, 200-209.

Anderson, A. K., Christoff, K., Stappen, I., Panitz, D., GhahreMANI, D. G., Glover, G., ET AL. (2003). Dissociated neural representations of intensity and valence in human olfaction. Nature Neuroscience, 6, 196-202.

Barrett, L. F. (2006). Are emotions natural kinds? Perspectives on Psychological Science, 1, 28-58.

Baumeister, R. F., Bratslavsky, E., Finkenauer, C., \& Vohs, K. (2001). Bad is stronger than good. Review of General Psychology, 5, 323-370.

Brett, M., Anton, J.-L., Valabregue, R., \& Poline, J.-B. (2002, June). Region of interest analysis using an SPM toolbox. Poster presented at the 8th International Conference on Functional Mapping of the Human Brain, Sendai, Japan.

Carstensen, L. L. (1993). Social and emotional patterns in adulthood: Support for socioemotional selectivity theory. Psychology \& Aging, 7, 331-338.

Carstensen, L. L., Fung, H., \& Charles, S. (2003). Socioemotional selectivity theory and the regulation of emotion in the second half of life. Motivation \& Emotion, 27, 103-123.

Carstensen, L. L., \& Mikels, J. A. (2005). At the intersection of emotion and cognition: Aging and the positivity effect. Current Directions in Psychological Science, 14, 117-121.

Charles, S. T., Mather, M., \& Carstensen, L. L. (2003). Aging and emotional memory: The forgettable nature of negative images for older adults. Journal of Experimental Psychology: General, 132, 310-324.

Collins, D. L., Zijdenbos, A. P., Kollokian, V., Sled, J. G., Kabani, N. J., Holmes, C. J., \& Evans, A. C. (1998). Design and construction of a realistic digital brain phantom. IEEE Transactions on Medical Imaging, 17, 463-468.

Cooney, R. E., Joormann, J., Atlas, L. Y., Eugene, F., \& Gotlib, I. H. (2007). Remembering the good times: Neural correlates of affect regulation. NeuroReport, 18, 1771-1774.

Daigneault, S., \& Braun, C. M. J. (1993). Working memory and the self-ordered pointing task: Further evidence of early prefrontal decline in normal aging. Journal of Clinical \& Experimental Neuropsychology, 15, 881-895.

Dale, A. M. (1999). Optimal experimental design for event-related fMRI. Human Brain Mapping, 8, 109-114.

D’Argembeau, A., Collette, F., Van der Linden, M., Laureys, S., Del Fiore, G., Degueldre, C., ET AL. (2005). Self-referential reflective activity and its relationship with rest: A PET study. NeuroImage, 25, 616-624.

DAVIDSON, R. J. (2002). Anxiety and affective style: Role of prefrontal cortex and amygdala. Biological Psychiatry, 51, 68-80.

Dolcos, F., LABAR, K. S., \& CABEZA, R. (2004). Dissociable effects of arousal and valence on prefrontal activity indexing emotional evalu- 
ation and subsequent memory: An event-related fMRI study. NeuroImage, 23, 64-74.

Drevets, W. C., \& Raichle, M. E. (1998). Reciprocal suppression of regional cerebral blood flow during emotional versus higher cognitive processes: Implications for interaction between emotion and cognition. Cognition \& Emotion, 12, 353-385.

FisHer, R. A. (1950). Statistical methods for research workers. London: Oliver \& Boyd.

Fung, H. H., Carstensen, L. L., \& Lutz, A. M. (1999). Influence of time on social preferences: Implications for life-span development. Psychology \& Aging, 14, 595-604.

Grimm, S., Schmidt, C. F., Bermpohl, F., Heinzel, A., Dahlem, Y., WYSS, M., ET AL. (2006). Segregated neural representation of distinct emotion dimensions in the prefrontal cortex: An fMRI study. NeuroImage, 30, 325-340.

Gross, J. J., Carstensen, L. L., Pasupathi, M., Tsai, J., Skorpen, C. G., \& Hsu, A. Y. C. (1997). Emotion and aging: Experience, expression, and control. Psychology \& Aging, 12, 590-599.

Gunning-Dixon, F. M., Gur, R. C., Perkins, A. C., Schroder, L., Turner, T., Turetsky, B. I., ET AL. (2003). Age-related differences in brain activation during emotional face processing. Neurobiology of Aging, 24, 285-295.

Gusnard, D. A., \& Raichle, M. E. (2001). Searching for a baseline: Functional imaging and the resting human brain. Nature Reviews Neuroscience, 2, 685-694.

Gutchess, A. H., Kensinger, E. A., \& Schacter, D. L. (2007). Aging, self-referencing, and medial prefrontal cortex. Social Neuroscience, 2, 117-133.

Hahn, S., Carlson, C., Singer, S., \& Gronlund, S. D. (2006). Aging and visual search: Automatic and controlled attentional bias to threat faces. Acta Psychologica, 123, 312-336.

Hansen, C. H., \& Hansen, R. D. (1988). Finding the face in the crowd: An anger superiority effect. Journal of Personality \& Social Psychology, 54, 917-924.

Heberlein, A. S., Padon, A. A., Gillihan, S. J., Farah, M. J., \& FelLows, L. K. (2008). Ventromedial frontal lobe plays a critical role in facial emotion recognition. Journal of Cognitive Neuroscience, 20, 721-733.

Hedden, T., \& Gabrieli, J. D. E. (2004). Insights into the ageing mind: A view from cognitive neuroscience. Nature Reviews Neuroscience, $\mathbf{5}, 87-97$

Iidaka, T., OKada, T., Murata, T., Omori, M., Kosaka, H., Sadato, N., \& YonEKURA, Y. (2002). Age-related differences in the medial temporal lobe responses to emotional faces as revealed by fMRI. Hippocampus, 12, 352-362.

Isaacowitz, D. M., Wadlinger, H. A., Goren, D., \& Wilson, H. R. (2006). Selective preference in visual fixation away from negative images in old age? An eye-tracking study. Psychology \& Aging, 21, 40-48.

IzARD, C. E. (2007). Basic emotions, natural kinds, emotion schemas, and a new paradigm. Perspectives on Psychological Science, 2, 260-280.

Johnson, S. C., Baxter, L. C., Wilder, L. S., Pipe, J. G., Heiserman, J. E., \& Prigatano, G. P. (2002). Neural correlates of self-reflection. Brain, 125, 1808-1814.

Johnson, S. C., Schmitz, T. W., Kawahara-Baccus, T. N., Rowley, H. A., Alexander, A. L., Lee, J., \& Davidson, R. J. (2005). The cerebral response during subjective choice with and without selfreference. Journal of Cognitive Neuroscience, 17, 1897-1906.

Kennedy, Q., Mather, M., \& Carstensen, L. L. (2004). The role of motivation in the age-related positive bias in autobiographical memory. Psychological Science, 15, 208-214.

KENSINGER, E. A. (2008). Age differences in memory for arousing and nonarousing emotional words. Journals of Gerontology, 63B, P13-P18.

Kensinger, E. A., Garoff-Eaton, R. J., \& Schacter, D. L. (2007). Effects of emotion on memory specificity in young and older adults. Journals of Gerontology, 62B, P208-P215.

Kensinger, E. A., \& LECLERC, C. M. (in press). Emotion processing, emotional memory, and aging. European Journal of Cognitive Psychology.

Kensinger, E. A., \& Schacter, D. L. (2006). Processing emotional pictures and words: Effects of valence and arousal. Cognitive, Affective, \& Behavioral Neuroscience, 6, 110-126.

Lane, R. D., Reiman, E. M., Ahern, G. L., Schwartz, G. E., \& DavidSON, R. J. (1997). Neuroanatomical correlates of happiness, sadness, and disgust. American Journal of Psychiatry, 154, 926-933.
Lane, R. D., Reiman, E. M., Bradley, M. M., Lang, P. J., Ahern, G. L., Davidson, R. J., \& Schwartz, G. E. (1997). Neuroanatomical correlates of pleasant and unpleasant emotion. Neuropsychologia, $\mathbf{3 5}$, 1437-1444.

Lang, P. J., Bradley, M. M., \& Cuthbert, B. N. (2005). International affective picture system (IAPS): Affective ratings of pictures and instruction manual (Technical Report A-6). University of Florida, Gainesville, FL.

Lawton, M. P., Kelban, M. H., Rajagopal, D., \& Dean, J. (1992). Dimensions of affective experience in three age groups. Psychology \& Aging, 7, 171-184.

Lazar, N. A., Luna, B., Sweeney, J. A., \& Eddy, W. F. (2002). Combining brains: A survey of methods for statistical pooling of information. NeuroImage, 16, 538-550.

Leclerc, C. M., \& Kensinger, E. A. (2008). Effects of age on detection of emotional information. Psychology \& Aging, 23, 209-215.

Mather, M. (2003). Aging and emotional memory. In D. Reisberg \& P. Hertel (Eds.), Memory and emotion (pp. 272-307). New York: Oxford University Press.

Mather, M. (2006). Why memories may become more positive with age. In B. Uttl, N. Ohta, \& A. Siegenthaler (Eds.), Memory and emotion: Interdisciplinary perspectives (pp. 135-159). Malden, MA: Blackwell.

Mather, M., Canli, T., English, T., Whitfield, S., Wais, P., OCHSNER, K., ET AL. (2004). Amygdala responses to emotionally valenced stimuli in older and younger adults. Psychological Science, 15, 259-263.

Mather, M., \& Carstensen, L. L. (2005). Aging and motivated cognition: The positivity effect in attention and memory. Trends in Cognitive Sciences, 9, 496-502.

Mather, M., \& Knight, M. [R.] (2005). Goal-directed memory: The role of cognitive control in older adults' emotional memory. Psychology \& Aging, 20, 554-570.

Mather, M., \& KNight, M. R. (2006). Angry faces get noticed quickly: Threat detection is not impaired among older adults. Journals of Gerontology, 61B, P54-P57.

Mittenberg, W., Seidenburg, M., O’leary, D. S., \& DiGiulio, D. V. (1989). Changes in cerebral functioning associated with normal aging. Journal of Clinical \& Experimental Neuropsychology, 11, 918-932.

Moscovitch, M., \& Winocur, G. (1995). Frontal lobes, memory, and aging. Annals of the New York Academy of Sciences, 769, 119-150.

OChSNer, K. N., Bunge, S. A., Gross, J. J., \& Gabrieli, J. D. E. (2002). Rethinking feelings: An fMRI study of the cognitive regulation of emotion. Journal of Cognitive Neuroscience, 14, 1215-1229.

Öhman, A., Flykt, A., \& Esteves, F. (2001). Emotion drives attention: Detecting the snake in the grass. Journal of Experimental Psychology: General, 130, 466-478.

PAnKsepp, J. (2007). Neurologizing the psychology of affects: How appraisal-based Constructivism and basic emotion theory can coexist. Perspectives on Psychological Science, 2, 281-296.

PARKIN, A. J. (1997). Normal age-related memory loss and its relation to frontal lobe dysfunction. In P. M. A. Rabbitt (Ed.), Methodology of frontal and executive function (pp. 177-190). Hove, U.K.: Psychology Press.

Phan, K. L., Wager, T., Taylor, S. F., \& Liberzon, I. (2002). Functional neuroanatomy of emotion: A meta-analysis of emotion activation studies in PET and fMRI. Neurolmage, 16, 331-348.

Pratto, F., \& John, O. P. (1991). Automatic vigilance: The attentiongrabbing power of negative social information. Journal of Personality \& Social Psychology, 61, 380-391.

Quirk, G. J., \& BeER, J. S. (2006). Prefrontal involvement in the regulation of emotion: Convergence of rat and human studies. Current Opinions in Neurobiology, 16, 723-727.

RAZ, N. (1996). Neuroanatomy of the aging brain observed in vivo: A review of structural MRI findings. In E. D. Bigler (Ed.), Neuroimaging II: Clinical applications (pp. 153-184). New York: Plenum.

Russell, J. A. (1980). A circumplex model of affect. Journal of Personality \& Social Psychology, 39, 1161-1178.

Samanez-Larkin, G. R., Gibbs, S. E. B., Khanna, K., Nielsen, L., Carstensen, L. L., \& Knutson, B. (2007). Anticipation of monetary gain but not loss in healthy older adults. Nature Neuroscience, $\mathbf{1 0}$, 787-791. 
Schmitz, T. W., Kawahara-Baccus, T. N., \& Johnson, S. C. (2004). Metacognitive evaluation, self-relevance, and the right prefrontal cortex. NeuroImage, 22, 941-947.

Shimamura, A. P. (1994). Neuropsychological perspectives on memory and cognitive decline in normal human aging. Seminars in the Neurosciences, 6, 387-394.

Small, D. M., Gregory, M. D., Mak, Y. E., Gitelman, D., Mesulam, M. M., \& PARRISH, T. (2003). Dissociation of neural representation of intensity and affective valuation in human gustation. Neuron, 39 , 701-711.

TAlairach, J., \& Tournoux, P. (1988). Co-planar stereotaxic atlas of the human brain. New York: Thieme Medical.

Tessitore, A., Hariri, A. R., Fera, F., Smith, W. G., Das, S., WeinBERger, D. R., \& MAtTAY, V. S. (2005). Functional changes in the activity of brain regions underlying emotion processing in the elderly. Psychiatry Research, 139, 9-18.

Urry, H. L., van Reekum, C. M., Johnstone, T., Kalin, N. H., ThuRow, M. E., Schaefer, H. S., ET AL. (2006). Amygdala and ventromedial prefrontal cortex are inversely coupled during regulation of negative affect and predict the diurnal pattern of cortisol secretion among older adults. Journal of Neuroscience, 26, 4415-4425.

WEST, R. L. (1996). An application of prefrontal cortex function theory to cognitive aging. Psychological Bulletin, 120, 272-292.

West, R. L. (2000). In defense of the frontal lobe hypothesis of cogni- tive aging. Journal of the International Neuropsychological Society, 6, 727-729.

Williams, L. M., Brown, K. J., Palmer, D., Liddell, B. J., KemP, A. H., Olivieri, G., ET AL. (2006). The mellow years? Neural basis of improving emotional stability over age. Journal of Neuroscience, 26, 6422-6430.

Wright, C. I., Wedig, M. M., Williams, D., Rauch, S. L., \& Albert, M. S. (2006). Novel fearful faces activate the amygdala in healthy young and elderly adults. Neurobiology of Aging, 27, 361-374.

ZALD, D. H., MATTSON, D. L., \& PARDO, J. V. (2002). Brain activity in ventromedial prefrontal cortex correlates with individual differences in negative affect. Proceedings of the National Academy of Sciences, 99, 2450-2454.

\section{NOTE}

1. As would be expected on the basis of the findings of Mather et al. (2004), activity in the older adults' amygdala was revealed at a standard threshold for the positive items, but was revealed for the negative items only when the threshold was lowered to $p<.05$. Although this general replication is heartening, because our analyses revealed no significant interaction between age and valence in the amygdala, we have chosen not to discusms this finding extensively in order to prevent ourselves from drawing conclusions based on nonsignificant trends.

\section{APPENDIX}

\section{Iable A1}

Regions Responding to Positive or Negative Images in Young or Older Adults

\begin{tabular}{|c|c|c|c|c|c|}
\hline Region & Hemisphere & $\begin{array}{c}\text { Talairach } \\
\text { Coordinates of } \\
\text { Peak Voxel } \\
(x, y, z)\end{array}$ & $\begin{array}{c}\text { MNI } \\
\text { Coordinates of } \\
\text { Peak Voxel } \\
(x, y, z)\end{array}$ & $\begin{array}{l}\text { Voxel } \\
\text { Extent }\end{array}$ & $\begin{array}{c}\text { Approximate } \\
\text { Brodmann } \\
\text { Area }\end{array}$ \\
\hline \multicolumn{6}{|c|}{ Younger Adults } \\
\hline \multicolumn{6}{|c|}{ Positive $>$ Neutral } \\
\hline Cuneus & Left & $-10,-94, \quad 21$ & $-10,-98, \quad 18$ & 44 & 19 \\
\hline Fusiform gyrus & Bilateral & $\begin{array}{r}44,-74,-10 \\
-44,-57,-14\end{array}$ & $\begin{array}{r}44,-76,-16 \\
-44,-58,-20\end{array}$ & $\begin{array}{l}67 \\
20\end{array}$ & $\begin{array}{l}19 \\
37\end{array}$ \\
\hline Inferior frontal gyrus & Right & 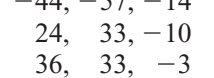 & $\begin{array}{r}-44,-58,-20 \\
24, \quad 34,-10 \\
36, \quad 34,-2\end{array}$ & $\begin{array}{l}20 \\
37\end{array}$ & $\begin{array}{l}37 \\
47 \\
47\end{array}$ \\
\hline Inferior temporal gyrus & Right & $50,-74,-1$ & $50,-76,-6$ & & 19 \\
\hline Medial frontal gyrus & Bilateral & $\begin{array}{rrr}0, & 49, & 44 \\
40, & 34, & -10\end{array}$ & $\begin{array}{rrr}0, & 48, & 50 \\
40, & 36, & -10\end{array}$ & 36 & $\begin{array}{r}8 \\
11\end{array}$ \\
\hline Middle occipital gyrus & Bilateral & $\begin{array}{rr}34,-89, & 8 \\
26,-91, & 5 \\
46,-78, & 4 \\
-24,-89, & 4\end{array}$ & $\begin{array}{cc}34,-92, & 4 \\
26,-94, & 0 \\
46,-80, & 0 \\
-24,-92, & 0\end{array}$ & 78 & $\begin{array}{l}19 \\
18 \\
19 \\
18\end{array}$ \\
\hline Parahippocampal gyrus & Right & $20,-22,-14$ & $20,-22,-18$ & 58 & 35 \\
\hline Superior frontal gyrus & Bilateral & $\begin{array}{rrr}4, & 36, & 52 \\
-12, & 49, & 42 \\
-10, & 64, & 8 \\
-10, & 32, & 52\end{array}$ & $\begin{array}{rrr}4, & 34, & 58 \\
-12, & 48, & 48 \\
-10, & 66, & 12 \\
-10, & 30, & 58\end{array}$ & $\begin{array}{l}37 \\
21\end{array}$ & $\begin{array}{r}8 \\
8 \\
10 \\
6\end{array}$ \\
\hline Superior temporal gyrus & Right & \multicolumn{3}{|c|}{ Negative $>$ Neutral } & 22 \\
\hline Inferior frontal gyrus & Left & $-44, \quad 29,-12$ & $-44, \quad 30,-12$ & 18 & 47 \\
\hline \multirow[t]{3}{*}{ Medial frontal gyrus } & Bilateral & $\begin{array}{rr}2, & 50,-16 \\
12, & 44,-11\end{array}$ & $\begin{array}{rr}2, & 52,-16 \\
12, & 46,-10\end{array}$ & 53 & $\begin{array}{l}11 \\
10\end{array}$ \\
\hline & & 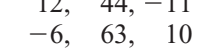 & 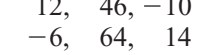 & 23 & $\begin{array}{l}10 \\
10\end{array}$ \\
\hline & & $46, \quad 18, \quad 43$ & $46, \quad 16, \quad 48$ & 21 & 8 \\
\hline Middle temporal gyrus & Right & $63,-52$ & $64,-54, \quad 2$ & 18 & 21 \\
\hline Precuneus & Right & $2,-48, \quad 48$ & $2,-52$ & 60 & 7 \\
\hline \multirow[t]{3}{*}{ Superior frontal gyrus } & Right & $4, \quad 41, \quad 50$ & $4, \quad 40$ & 28 & 8 \\
\hline & & $4, \quad 58, \quad 27$ & $4, \quad 58, \quad 32$ & 32 & 9 \\
\hline & & $10, \quad 59, \quad 19$ & $10, \quad 60, \quad 24$ & & 10 \\
\hline \multirow[t]{3}{*}{ Superior temporal gyrus } & Right & $48,-57, \quad 19$ & $48,-60, \quad 18$ & 195 & 39 \\
\hline & & $59,-55, \quad 19$ & $60,-58, \quad 18$ & & 22 \\
\hline & & $50,-8,-11$ & $50,-8,-14$ & 43 & 21 \\
\hline
\end{tabular}


APPENDIX (Continued)

\begin{tabular}{|c|c|c|c|c|c|}
\hline \multicolumn{6}{|c|}{ Table A1 (Continued) } \\
\hline Region & Hemisphere & $\begin{array}{l}\text { Talairach } \\
\text { Coordinates of } \\
\text { Peak Voxel } \\
(x, y, z)\end{array}$ & $\begin{array}{c}\text { MNI } \\
\text { Coordinates of } \\
\text { Peak Voxel } \\
(x, y, z)\end{array}$ & \multirow[t]{2}{*}{$\begin{array}{c}\text { Voxel } \\
\text { Extent }\end{array}$} & $\begin{array}{c}\text { Approximate } \\
\text { Brodmann } \\
\text { Area }\end{array}$ \\
\hline \multicolumn{5}{|c|}{ Older Adults } & \\
\hline \multicolumn{6}{|c|}{ Positive $>$ Neutral } \\
\hline Anterior cingulate & Left & $-12, \quad 29,-3$ & $-12, \quad 30, \quad-2$ & 23 & 32 \\
\hline Fusiform gyrus & Bilateral & $44,-51,-11$ & $44,-52,-16$ & 131 & 37 \\
\hline & & $-42,-37,-12$ & $-42,-38,-16$ & 30 & 20 \\
\hline Inferior frontal gyrus & Right & $46, \quad 28, \quad 15$ & $46, \quad 28, \quad 18$ & & 46 \\
\hline Insula & Right & $30, \quad 18, \quad 18$ & $30, \quad 18, \quad 20$ & & 13 \\
\hline Middle frontal gyrus & Left & $-22, \quad 44,-12$ & $-22, \quad 46,-12$ & 29 & 11 \\
\hline \multirow[t]{2}{*}{ Middle occipital gyrus } & Right & $48,-72, \quad 7$ & $48,-74, \quad 4$ & & 19 \\
\hline & & $26,-83$ & $26,-86$ & 20 & 18 \\
\hline \multirow[t]{7}{*}{ Middle temporal gyrus } & Bilateral & $48,-67, \quad 14$ & $48,-70, \quad 12$ & 148 & 39 \\
\hline & & $50,-60, \quad 12$ & $50,-62, \quad 10$ & & 39 \\
\hline & & $-63,-43, \quad 2$ & $-64,-44, \quad 0$ & 63 & 21 \\
\hline & & $-59,-50, \quad 1$ & $-60,-52,-2$ & & 21 \\
\hline & & $-46,-33,-3$ & $-46,-34,-6$ & 19 & 21 \\
\hline & & $-46,-71, \quad 16$ & $-46,-74, \quad 14$ & 64 & 39 \\
\hline & & $-53,-65, \quad 25$ & $-54,-68, \quad 24$ & & 39 \\
\hline Subgyral & Right & $50,-43,-5$ & $50,-44,-8$ & & 37 \\
\hline \multirow[t]{3}{*}{ Superior temporal gyrus } & Bilateral & $-55,-50, \quad 8$ & $-56,-52, \quad 6$ & & 22 \\
\hline & & $59,-50, \quad 10$ & $60,-52$ & 23 & 22 \\
\hline & & Negative $>$ Neut & & & \\
\hline \multirow[t]{2}{*}{ Fusiform gyrus } & Bilateral & $-40,-64,-7$ & $-40,-66,-12$ & 21 & 19 \\
\hline & & $48,-45,-13$ & $48,-46,-18$ & 77 & 37 \\
\hline Inferior parietal lobule & Right & $42,-43, \quad 41$ & $42,-46, \quad 42$ & 27 & 40 \\
\hline Insula & Right & $32, \quad 24$, & $32, \quad 24$, & & 13 \\
\hline \multirow[t]{2}{*}{ Middle frontal gyrus } & Bilateral & $50, \quad 27$ & $50, \quad 26$ & 18 & 9 \\
\hline & & $-40, \quad 19$ & $-40, \quad 18$ & 40 & 46 \\
\hline Middle occipital gyrus & Right & $26,-83$ & $26,-86$ & 53 & 18 \\
\hline \multirow[t]{4}{*}{ Middle temporal gyrus } & Bilateral & $48,-67$ & $48,-70$ & 169 & 39 \\
\hline & & $-50,-69$ & $-50,-72$ & 324 & 39 \\
\hline & & $-55,-60$ & $-56,-62$ & & 37 \\
\hline & & $-55,-50$ & $-56,-52$ & & 22 \\
\hline Precentral gyrus & Left & $-38,-2, \quad 39$ & $-38,-4, \quad 42$ & 28 & 6 \\
\hline \multirow{3}{*}{ Precuneus } & Bilateral & $18,-70, \quad 42$ & $18,-74$ & 28 & 7 \\
\hline & & $10,-51$ & $10,-54$ & 26 & 31 \\
\hline & & $-20,-75$ & $-20,-80$ & 24 & 7 \\
\hline
\end{tabular}

Table A2

Regions Activating on the Basis of Arousal for Younger and Older Adults

\begin{tabular}{lccccc}
\hline \multicolumn{1}{c}{ Region } & Hemisphere & $\begin{array}{c}\text { Talairach } \\
\text { Coordinates of } \\
\text { Peak Voxel } \\
(x, y, z)\end{array}$ & $\begin{array}{c}\text { MNI } \\
\text { Coordinates of } \\
\text { Peak Voxel } \\
(x, y, z)\end{array}$ & $\begin{array}{c}\text { Voxel } \\
\text { Extent }\end{array}$ & $\begin{array}{c}\text { Approximate } \\
\text { Brodmann } \\
\text { Area }\end{array}$ \\
\hline Medial frontal gyrus & Right & $8,61,15$ & $8,62,20$ & 6 & 10 \\
Middle temporal gyrus & Left & $-51,-63,18$ & $-52,-66,16$ & 39 & 39 \\
\hline
\end{tabular}

Note-Regions were revealed by a four-way conjunction analysis - that is, positive $>$ neutral for young adults AND negative $>$ neutral for young adults AND positive $>$ neutral for older adults AND negative $>$ neutral for older adults. 
APPENDIX (Continued)

Table A3

Regions Activating Similarly on the Basis of Valence for Younger and Older Adults

\begin{tabular}{|c|c|c|c|c|c|}
\hline Region & Hemisphere & $\begin{array}{c}\text { Talairach } \\
\text { Coordinates of } \\
\text { Peak Voxel } \\
(x, y, z)\end{array}$ & $\begin{array}{c}\text { MNI } \\
\text { Coordinates of } \\
\text { Peak Voxel } \\
(x, y, z)\end{array}$ & $\begin{array}{l}\text { Voxel } \\
\text { Extent }\end{array}$ & $\begin{array}{c}\text { Approximate } \\
\text { Brodmann } \\
\text { Area }\end{array}$ \\
\hline \multicolumn{6}{|c|}{ Positive $>$ Negative } \\
\hline Precentral gyrus & Bilateral & 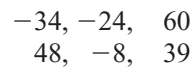 & $\begin{array}{rr}-34,-28, & 64 \\
48,-10, & 42\end{array}$ & $\begin{array}{r}8 \\
10\end{array}$ & $\begin{array}{l}4 \\
6\end{array}$ \\
\hline Superior frontal gyrus & Right & 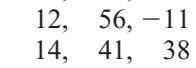 & 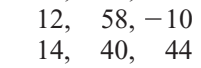 & $\begin{array}{l}9 \\
5\end{array}$ & $\begin{array}{r}10 \\
8\end{array}$ \\
\hline Cingulate gyrus & Left & $-4,-24, \quad 25$ & $-4,-26, \quad 26$ & 15 & 23 \\
\hline Amygdalohippocampal complex & Right & $32,-5,-18$ & $32,-4,-22$ & 33 & \\
\hline Cuneus & Right & $\begin{array}{ll}22,-88, & 25 \\
12,-90, & 23 \\
16,-85, & 12\end{array}$ & $\begin{array}{rr}22,-92, & 22 \\
12,-94, & 20 \\
16,-88, & 8\end{array}$ & 171 & $\begin{array}{l}19 \\
19 \\
18\end{array}$ \\
\hline Lingual gyrus & Bilateral & 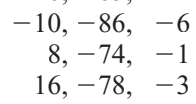 & $\begin{array}{r}-10,-88,-12 \\
8,-76,-6 \\
16,-80,-8\end{array}$ & $\begin{array}{r}13 \\
7 \\
15\end{array}$ & $\begin{array}{l}18 \\
18 \\
18\end{array}$ \\
\hline Middle temporal gyrus & Right & $55,-1,-13$ & $56, \quad 0,-16$ & 7 & 21 \\
\hline \multicolumn{6}{|c|}{ Negative $>$ Positive } \\
\hline Inferior frontal gyrus & Right & $\begin{array}{llr}51, & 11, & 31 \\
44, & 33, & 9\end{array}$ & $\begin{array}{lll}52, & 10, & 34 \\
44, & 34, & 12\end{array}$ & 26 & $\begin{array}{r}9 \\
46\end{array}$ \\
\hline Middle frontal gyrus & Right & $46, \quad 8, \quad 36$ & $46, \quad 6, \quad 40$ & 72 & 9 \\
\hline Thalamus & Left & $-6,-25, \quad 0$ & $-6,-26,-2$ & 42 & \\
\hline Superior temporal gyrus & Right & $44,-56, \quad 16$ & $44,-58, \quad 14$ & 6 & 22 \\
\hline
\end{tabular}

Note-Regions were revealed by a conjunction analysis - that is, positive $>$ negative in young adults AND positive $>$ negative in older adults.

Table A4

Regions Showing an Interaction Between Age and Valence

\begin{tabular}{|c|c|c|c|c|c|}
\hline Region & Hemisphere & $\begin{array}{c}\text { Talairach } \\
\text { Coordinates of } \\
\text { Peak Voxel } \\
(x, y, z)\end{array}$ & $\begin{array}{c}\text { MNI } \\
\text { Coordinates of } \\
\text { Peak Voxel } \\
(x, y, z)\end{array}$ & $\begin{array}{l}\text { Voxel } \\
\text { Extent }\end{array}$ & $\begin{array}{c}\text { Approximate } \\
\text { Brodmann } \\
\text { Area }\end{array}$ \\
\hline Middle frontal gyrus & Left & $-36, \quad 25, \quad 43$ & $-36, \quad 24$ & 34 & 8 \\
\hline Anterior cingulate & Bilateral & $\begin{array}{rrr}0, & 39, & -5 \\
\end{array}$ & $\begin{array}{rrr}0, & 40, & -4\end{array}$ & 38 & 32 \\
\hline Angular gyrus & Left & 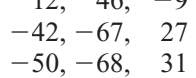 & $\begin{array}{rrr}12, & 48, & 8 \\
-50, & 70, & 26 \\
-72, & 30\end{array}$ & $\begin{array}{r}22 \\
102\end{array}$ & $\begin{array}{l}32 \\
39 \\
39\end{array}$ \\
\hline Precuneus & Left & $-4,-52$ & $-4, \quad 56$ & 19 & 7 \\
\hline Thalamus & Left & $0,-19$ & $0,-20$ & 30 & \\
\hline
\end{tabular}

Note-All regions identified by this contrast analysis showed an age-related valence reversal - that is, negative $>$ positive for younger AND positive $>$ negative for older. 